\title{
Amino Acid (Leucine) Chromatography: A Study of Branched-Chain Aminoaciduria in Type 2 Diabetes
}

Bhagavan Reddy Kolanu ${ }^{1}$, Venugopal Boddula ${ }^{1}$, Sabitha Vadakedath ${ }^{1}$, Venkataramana Kandi 2

1. Biochemistry, Prathima Institute of Medical Sciences, Karimnagar, IND 2. Microbiology, Prathima Institute of Medical Sciences, Karimnagar, IND

$\square$ Corresponding author: Venkataramana Kandi, ramana20021@gmail.com Disclosures can be found in Additional Information at the end of the article

\section{Abstract}

\section{Introduction}

Diabetes is a disease characterized by insulin deficiency resulting in glucose intolerance and in abnormalities of other metabolic fuels including protein. Recently, a number of studies have revealed that branched-chain amino acids (BCAAs) (leucine, isoleucine, and valine) play an important role in the regulation of protein synthesis by activating mammalian target of rapamycin (mTOR) in pancreatic $\beta$ cells. BCAAs have positive effects on the regulation of glucose homeostasis. Leucine is an important nutrient signal as evidenced by recent observations, which showed increased fasting concentrations of circulating BCAAs being associated with an increased risk of type 2 diabetes (T2D) and insulin resistance in humans. Leucine seems to have direct effects on hypothalamic and brainstem functioning involved in satiety, which can potentially contribute to obesity and T2D. A number of observational studies indicate that elevated activity of BCAAs could be associated with poor metabolic health and T2D complications. Although these associations were consistently observed in humans, the mechanisms underlying this relationship remain to be completely understood. In this study, we have attempted to evaluate urinary excretion of leucine among patients of T2D and compared them with healthy controls by using a low-cost and non-invasive amino acid chromatography technique.

\section{Methods}

The study was carried out in the Department of Biochemistry, Central Research Unit, Prathima Institute of Medical Sciences (PIMS), Karimnagar, Telangana, India, during the period between July and September 2016. A group of 55 normal healthy subjects (control group A), and 55

Received 02/21/2017 Review began 03/03/2017 Review ended 03/05/2017 Published 03/12/2017

\section{๑) Copyright 2017}

Kolanu et al. This is an open access article distributed under the terms of the Creative Commons Attribution License CC-BY 3.0., which permits unrestricted use, distribution, and reproduction in any medium, provided the original author and source are credited. patients suffering from T2D on treatment (test group B), were enrolled in the study. The urine samples were collected from normal and T2D subjects. Thin-layer chromatography (TLC) for leucine was performed on all the urine samples.

\section{Results}

A strong correlation ( $\mathrm{p}=0.0004)$ was found between the urinary excretion of leucine among the control $(\mathrm{Rf}=0.174 \pm 0.089)$ and $\mathrm{T} 2 \mathrm{D}(\mathrm{Rf}=0.247 \pm 0.030)$ patients.

\section{Conclusion}

Excretion of BCAAs (leucine) in detectable and increased quantities reflect the presence of an altered metabolic state attributable to T2D, which in turn could lead to early diabetic

\section{How to cite this article}

Kolanu B, Boddula V, Vadakedath S, et al. (March 12, 2017) Amino Acid (Leucine) Chromatography: A Study of Branched-Chain Aminoaciduria in Type 2 Diabetes. Cureus 9(3): e1091. DOI 10.7759/cureus.1091 
complications. This method (TLC), being non-invasive and cost-effective, could be recommended for assessing the progression and management of type 2 diabetes patients.

Categories: Endocrinology/Diabetes/Metabolism, Endocrinology/Diabetes/Metabolism Keywords: leucine, thin-layer chromatography (tlc), mammalian target of rapamycin (mtor), branched chain aminoacids (bcaa's), type 2 diabetes (t2d)

\section{Introduction}

The prevalence of type 2 diabetes (T2D) is increasing worldwide, as evidenced from the fact that more than $90 \%$ of individuals suffer from T2D compared to type 1 diabetes. The major feature of obesity and T2D is a metabolic syndrome which increases the risk of coronary heart diseases, cancer, neurodegenerative disorders, and other metabolic abnormalities [1]. Sedentary lifestyles and dietary habits account for the increased rates of diabetes in India. Food habits in India have changed from traditional to processed foods with more calories, more oil, ghee, and dalda, and less protein, which again is a risk factor for T2D [2]. We know the role played by proteins and amino acids in regulating cell growth and proliferation. Leucine is one of the essential branched-chain amino acids (BCAAs), along with valine and isoleucine, having a role in insulin secretion, regulating protein turnover, and protein synthesis [3-4]. The enzyme branched-chain amino acid transaminase (BCAT) is the one which transaminates the BCAAs to corresponding alpha keto acids. There are two forms of BCAT enzymes, one present in mitochondria, which is active in multiple tissues, but absent in the liver and gut. The cytosolic form active in the brain and peripheral tissues makes the BCAAs bypass porto-venous circulation. Leucine is an important nutrient sensor along with other BCAAs, as noted by their increased fasting levels indicating a risk factor for T2D, insulin resistance, and other metabolic diseases. Leucine has a direct effect on hypothalamic and brainstem processes involved in satiety [5] and can regulate the release of hormones like leptin and ghrelin that can potentially affect food intake and glucose levels [6-7]. The present study aims to know the levels of leucine excreted in urine by T2D patients when compared to controls.

\section{Materials And Methods}

The study group included 55 patients having T2D attending the outpatient ward of Prathima Institute of Medical Sciences, Karimnagar, Telangana, and 55 normal healthy controls, in the age group of 30-65 years. The study was approved by the institutional ethical committee. Urine samples of all subjects were collected for analysis after obtaining informed consent. In all the urine samples, the migration of leucine amino acid was carried out using thin-layer chromatography (TLC).

\section{Thin-layer chromatography (TLC)}

TLC is a quick, inexpensive microscale technique used to measure amino acid migration, which is calculated as retardation factor (Rf).

TLC was standardized in our laboratory by using standard amino acids. In the present study, ready-made TLC plates were used for analysis. The solvent used here constituted a mixture of butanol, acetic acid, and water in the ratio of 4:1:5. The standard amino acid used for comparing the migration of amino acid is a $2 \%$ solution of leucine.

A small amount of the urine sample (approximately two drops) was dispensed with a capillary tube on a TLC plate and was allowed to dry. The plate was then carefully placed in a trough containing the solvent mixture (butanol, acetic acid, and water at a ratio of $4: 1: 5$ ). The watery 


\title{
Cureus
}

component of the solvent mixture binds to the inert support on the plate and serves as a stationary phase. The sample component, which migrates on the plate, is considered as the mobile phase. Separation occurs due to the difference in the solubilities of the mobile and stationary phases. The whole process of separation took around two hours, after which the TLC plate was dried and later sprayed with a coloring reagent (ninhydrin) that helps in visualization of migration. The length of migration was simultaneously compared with standards, and the corresponding Rf values were calculated using the formula as shown in Figure 1.

\section{$\mathrm{Rf}=$ Distance travelled by solute Distance travelled by solvent}

\author{
$\mathrm{Rf}=$ retardation factor or ratio-to-front value expressed \\ in decimal fraction
}

FIGURE 1: Formula to calculate the retardation factor (Rf) value

\section{Results}

The results of TLC was recorded as retardation factor (Rf) value. A 'p' value of 0.0004 was observed between the two groups, revealing statistical significance as shown in Table 1 .

\section{Thin-layer chromatography \\ (TLC)}

Rf Value
Group-A (Control) $n=25$

Mean \pm SD

$0.174 \pm 0.089$

\author{
Group-B (Type 2-DM) n=25 \\ Mean \pm SD
}

$0.247 \pm 0.030$
' $p$ '

VALUE

$0.0004^{*}$

TABLE 1: Comparision of thin-layer chromatography of leucine among control and test groups

\section{Discussion}

In $\mathrm{T} 2 \mathrm{D}$, there is either progressive degeneration of pancreatic islet cells or receptor defect for insulin. Increased rates of proliferation of pancreatic $\beta$ cells as well as apoptosis were also noted in diabetes [8]. Leucine stimulates $\beta$ cell proliferation via nutrient signaling, activates Rag guanosine triphosphatases (GTPases), activates mammalian target of rapamycin complex 1 (mTORC1), and increases translational protein activity, which forms a hallmark feature of T2D as evidenced from studies in experimental mice [9]. Leucine can also trigger triglyceride synthesis in the liver by activating sterol regulatory element binding protein (SREBP) and overactivating folding of newly synthesized protein in the endoplasmic reticulum (ER), thus causing $\beta$ cell dysfunction and death, which can lead to T2D [10]. 
In obesity, the uptake of BCAAs by adipose tissue is less when compared to skeletal muscle. In obesity, there is muscular atrophy due to increased cortisol levels due to changes in Kruppellike factor 15 (KLF15) in skeletal muscle. The KLF 15 upregulates gene expression of branchedchain aminotransferase 2 (BCAT 2), which could later contribute to insulin resistance [11-12].

\section{Role of leucine in insulin secretion}

In pancreatic $\beta$ cells, leucine simulates the release of insulin and provides amino group for increased transportation across the membrane by means of activating the glutamate dehydrogenase (GLDH) enzyme. Leucine regulates gene transcription and protein synthesis in pancreatic $\beta$ cells via mammalian target of rapamycin (mTOR) signaling, or it can directly incorporate ribosomes for protein synthesis [13].

\section{mTOR dependent signaling of leucine}

Leucine is one of the nutrient sensors regulating the mTOR protein complex. mTOR is a multidomain protein; in mammals, there are two complexes - mTORC1 and mTORC2 respectively. mTORC1 consists of mTOR, regulatory-associated protein of mTOR (raptor), G protein beta subunit-like (GRL), and DEP domain-containing mTOR-interacting protein (DEPTOR). Its function is to regulate cell growth and proliferation. mTORC2 is made of mTOR, rapamycininsensitive companion of mammalian target of rapamycin (Rictor), GßL, stress-activated protein kinase-interacting 1 (Sin 1), proline-rich protein 5 (PRR5), and DEPTOR protein; it promotes cellular survival, regulates cytoskeletal dynamics, and controls ion transport as well as cell growth [14-15]. There is aberrant signaling of mTOR during conditions like cancer, cardiovascular disease (CVD), and diabetes.

In this pathway, leucine inhibits adenosine mono phosphate protein kinase (AMPK) because of the energy generated in the muscle cells by it, and there is phosphorylation of eukaryotic translation initiation factor $4 \mathrm{G}$ protein (eIF4G) and ribosomal protein $\mathrm{P}^{70} \mathrm{~S} 6$ kinase as shown in Figure 2. All these events lead to recruiting ribosomes for protein synthesis [16-18]. 


\section{Cureus}

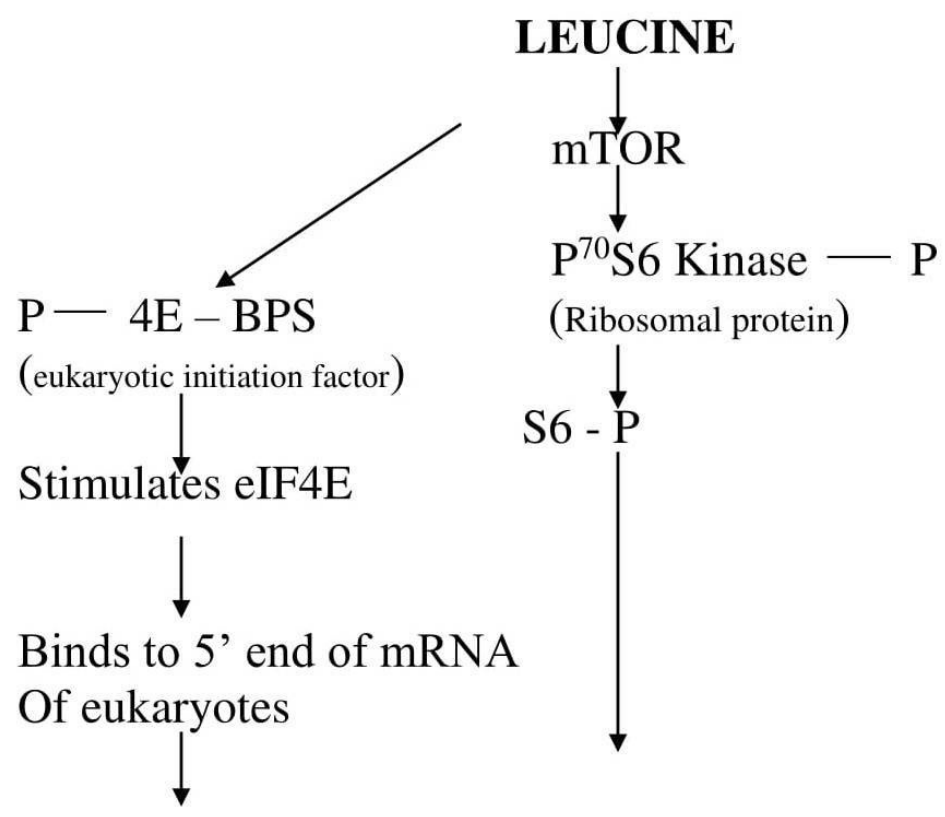

FACILITATES RIBOSOMES FOR PROTEIN SYNTHESIS

P: Phosphorylation

mTOR: Mechanistic target of rapamycin

$\mathbf{P}^{70}$ S6 Kinase: Ribosomal protein S6 kinase beta-1 (S6K1)

eIF4E : Eukaryotic translation initiation factor $4 \mathrm{E}$

BPS: Body protein synthesis

S6: Ribosomal protein S6

mRNA: Messenger Ribonucleic acid

FIGURE 2: mTOR dependent protein synthesis by leucine

\section{mTOR independent signaling by Leucine}

Leucine can initiate protein synthesis without mTOR association and can synthesize protein as shown in Figure 3. 


\title{
LEUCINE
}

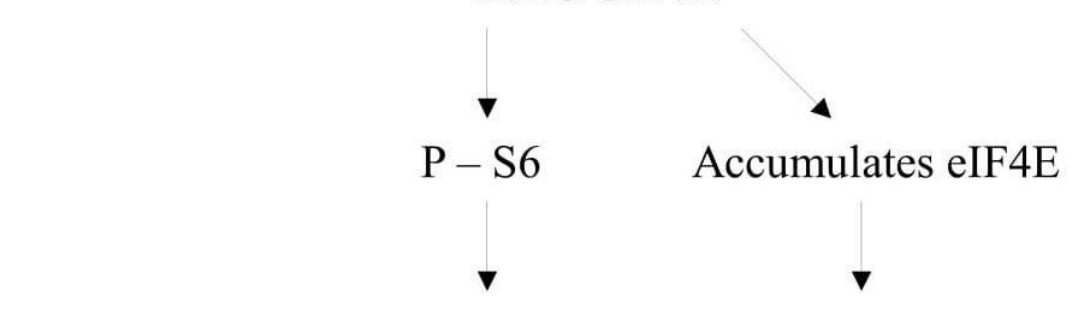

RECRUITS RIBOSOMES FOR PROTEIN SYNTHESIS

\author{
P: Phosphorylation \\ S6: Ribosomal protein S6 \\ eIF4E : Eukaryotic translation initiation factor 4E
}

FIGURE 3: mTOR independent protein synthesis by leucine

It was found in experimental animals that leucine alone can phosphorylate serine residues at 1108,1148 , and 1192 of C-terminal end of eIF4G, forming a complex of eIF4G and eukaryotic translation initiation factor $4 \mathrm{E}$ (eIF4E). Thus, it initiates protein synthesis by translation, especially in skeletal muscles irrespective of fiber type [19-20].

Many previous studies have reported the role of circulating and dietary BCAAs and their potential role in the development and progression of various diseases including T2D [21-25]. This is probably the first report which compared the excretion of leucine in urine among T2D patients with the controls negative for T2D. Detection of leucine in blood circulation is a rather invasive and costly method which can be replaced by studying urinary excretion of BCAAs.

\section{Conclusions}

Diagnosis and management of patients suffering from T2D assume greater significance, because if it is not controlled, the patients may suffer from various complications including chronic kidney diseases, cardiovascular disease, neurological disease, and other metabolic disorders.The study results have emphasized the probable role of BCAAs and their excretion on the progression of T2D. Future studies are warranted to investigate the importance of BCAAs, and their supplementation in the management of various metabolic disorders including T2D. Leucine, including other BCAAs and the genes coding for their catabolism, could well be potential biomarkers for the diagnosis and management of various metabolic disorders.

\section{Additional Information \\ Disclosures}

Human subjects: Consent was obtained by all participants in this study. PIMS-IEC issued approval PIMS/IEC/2016-18610. Animal subjects: All authors have confirmed that this study did not involve animal subjects or tissue. Conflicts of interest: In compliance with the ICMJE uniform disclosure form, all authors declare the following: Payment/services info: All authors have declared that no financial support was received from any organization for the submitted work. Financial relationships: All authors have declared that they have no financial relationships at present or within the previous three years with any organizations that might have an interest in the submitted work. Other relationships: All authors have declared that 
there are no other relationships or activities that could appear to have influenced the submitted work.

\section{References}

1. Wild S, Roglic G, Green A, Sicree R, King H: Global prevalence of diabetes: estimates for the year 2000 and projections for 2030. Diabetes Care. 2004, 27:1047-1053. 10.2337/diacare.27.5.1047

2. Hu FB, Manson JE, Stampfer MJ, Colditz G, Liu S, Solomon CG, Willett WC: Diet, lifestyle, and the risk of type 2 diabetes mellitus in women. N Engl J Med. 2001, 345:790-7. 10.1056/NEJMoa010492

3. Rosenthal J, Angel A, Farkas J: Metabolic fate of leucine: a significant sterol precursor in adipose tissue and muscle. Am J Physiol. 1974, 226:411-418.

4. Cahill GF Jr, Aoki TT, Brennan MF, Müller WA: Insulin and muscle amino acid balance . Proc Nutr Soc. 1972, 31:233-8. 10.1079/PNS19720042

5. Blouet C, Jo YH, Li X, Schwartz GJ: Mediobasal hypothalamic leucine sensing regulates food intake through activation of a hypothalamus-brainstem circuit. J Neurosci. 2009, 29:8302-11. 10.1523/JNEUROSCI.1668-09.2009

6. Schwartz GJ: Central leucine sensing in the control of energy homeostasis . Endocrinol Metab Clin North Am. 2013, 42:81-7. 10.1016/j.ecl.2012.12.001

7. Chen H, Simar D, Ting JH, Erkelens JR, Morris MJ: Leucine improves glucose and lipid status in offspring from obese dams, dependent on diet type, but not caloric intake. J

Neuroendocrinol. 2012, 24:1356-64. 10.1111/j.1365-2826.2012.02339.x

8. Ackermann AM, Gannon M: Molecular regulation of pancreatic beta-cell mass development, maintenance, and expansion. J Mol Endocrinol. 2007, 38:193-206. 10.1677/JME-06-0053

9. Gluckman PD, Hanson MA: Living with the past: evolution, development, and patterns of disease. Science. 2004, 305:1733-6. 10.1126/science.1095292

10. Peterson TR, Sengupta SS, Harris TE, et al.: mTOR complex 1 regulates lipin 1 localization to control the SREBP pathway. Cell. 2011, 146:408-20. 10.1016/j.cell.2011.06.034

11. Karunakaran U, Kim HJ, Kim JY, Lee IK: Guards and culprits in the endoplasmic reticulum: glucolipotoxicity and $\beta$-cell failure in type II diabetes. Exp Diabetes Res. 2012, 2102:639762. 10.1155/2012/639762

12. Gray S, Wang B, Orihuela Y, et al.: Regulation of gluconeogenesis by Krüppel-like factor 15 . Cell Metab. 2007, 5:305-12. 10.1016/j.cmet.2007.03.002

13. Yang J, Chi Y, Burkhardt BR, Guan Y, Wolf BA: Leucine metabolism in regulation of insulin secretion from pancreatic beta cells. Nutr Rev. 2010, 68:270-279. 10.1111/j.17534887.2010.00282.x

14. Dowling RJ, Topisirovic I, Fonseca BD, Sonenberg N: Dissecting the role of mTOR: lessons from mTOR inhibitors. Biochim Biophys Acta. 2010, 1804:433-9.

10.1016/j.bbapap.2009.12.001

15. Laplante M, Sabatini DM: Regulation of mTORC1 and its impact on gene expression at a glance. J Cell Sci. 2013, 126:1713-9. 10.1242/jcs.125773

16. Du M, Shen QW, Zhu MJ, Ford SP: Leucine stimulates mammalian target of rapamycin signaling in C2C12 myoblasts in part through inhibition of adenosine monophosphateactivated protein kinase. J Anim Sci. 2007, 85:919-27. 10.2527/jas.2006-342

17. Avruch J, Long X, Ortiz-Vega S, Rapley J, Papageorgiou A, Dai N: Amino acid regulation of TOR complex 1. Am J Physiol Endocrinol Metab. 2009, 296:E592-602.

10.1152/ajpendo.90645.2008

18. Inoki K, Ouyang H, Li Y, Guan KL: Signaling by target of rapamycin proteins in cell growth control. Microbiol Mol Biol Rev. 2005, 69:79-100. 10.1128/MMBR.69.1.79-100.2005

19. Raught B, Gingras AC, Gygi SP, Imataka H, Morino S, Gradi A, Aebersold R, Sonenberg N: Serum-stimulated, rapamycin-sensitive phosphorylation sites in the eukaryotic translation initiation factor 4GI. EMBO J. 2000, 19:434-44. 10.1093/emboj/19.3.434

20. Bolster DR, Vary TC, Kimball SR, Jefferson LS: Leucine regulates translation initiation in rat skeletal muscle via enhanced eIF4G phosphorylation. J Nutr. 2004, 134:1704-10.

21. Magnusson M, Lewis GD, Ericson U, et al.: A diabetes-predictive amino acid score and future cardiovascular disease. Eur Heart J. 2013, 34:1982-1989. 10.1093/eurheartj/ehs424

22. Ruiz-Canela M, Toledo E, Clish CB, et al.: Plasma branched-chain amino acids and incident 


\section{Cureus}

cardiovascular disease in the PREDIMED trial. Clin Chem. 2016, 62:582-592.

10.1373/clinchem.2015.251710

23. Pallares-Méndez R, Aguilar-Salinas CA, Cruz-Bautista I, Del Bosque-Plata L: Metabolomics in diabetes, a review. Ann Med. 2016, 48:89-102. 10.3109/07853890.2015.1137630

24. Zhao X, Gang X, Liu Y, Sun C, Han Q, Wang G: Using metabolomic profiles as biomarkers for insulin resistance in childhood obesity: a systematic review. J Diabetes Res. 2016, 2016:8160545. 10.1155/2016/8160545

25. Zhao X, Han Q, Liu Y, Sun C, Gang X, Wang G: The relationship between branched-chain amino acid related metabolomic signature and insulin resistance: a systematic review. J Diabetes Res. 2016, 2016:2794591. 10.1155/2016/2794591 